\title{
FURTHER DEVELOPMENTS IN SURFACE IMAGING RESISTS
}

\author{
Donald W. Johnson ${ }^{1}$, Roderick R. Kunz ${ }^{2}$ and Mark W. Horn ${ }^{2}$ \\ 1. Microlithography Chemical Company, 294 Pleasant Street, Watertown, MA 02172, USA \\ 2. Lincoln Laboratory, Massachusetts Institute of Technology, 244 Wood Street, Lexington, \\ $M A 02173, U S A$.
}

\begin{abstract}
At present one of the most promising production-worthy $193 \mathrm{~nm}$ resist approaches is a single layer, dry developed, surface imaging, silylation process. An evaluation of commercially available developmental resists shows excellent process versatility and lithographic performance. An evaluation of silylation conditions shows more versatility than previously demonstrated. No flow is seen in silylated features, leading to excellent dimensional control and edge profiles. Preliminary results indicate better than $0.18 \mu \mathrm{m}$ resolution and linearity to $0.20 \mu \mathrm{m}$ without the use of phase shift masks. Geometries of $0.1 \mu \mathrm{m}$ have been demonstrated in a resist process which is available for evaluation of $0.20 \mu \mathrm{m}$ devices processes as well as $256 \mathrm{MB}$ DRAM circuits.
\end{abstract}

\section{INTRODUCTION}

Recent research efforts have begun to evaluate very deep UV (VUV) lithography and have already shown it to be capable of sub- $0.25 \mu \mathrm{m}$ linewidths.[1-7] The ArF excimer laser at 193 $\mathrm{nm}$ is a natural candidate as the VUV source, since it is very similar to its $\mathrm{KrF}, 248 \mathrm{~nm}$ predecessor. The theoretical resolution of $193 \mathrm{~nm}$ lithography using phase shift masks is 0.25 $\lambda / \mathrm{NA}$, or less than $0.1 \mu \mathrm{m}(100 \mathrm{~nm})$ for NA greater than 0.50 . The major needs of this technology are the development of the alignment and exposure tool and the development of acceptable photoresist materials and processes.

At present, the most promising production worthy resist approach is a dry-developed, surface imaging, single-layer resist process.[1,4,5] The ultimate would be a planarized, single-layer resist utilizing this approach. There have also been several recent developments in transparent, single layer methacrylate based resists.[7-9] More work needs to be done on these systems to improve their generally low etch resistance and overcome thin film interference effects. In the surface imaging process, Figure 1, the photoresist is exposed to form a latent image in only a thin top section of the resist film. The resist is then treated with a silicon-containing vapor to introduce silicon selectively into the unexposed areas. No post exposure bake is required either before or after silylation. In a subsequent oxygen plasma reactive ion etch (RIE) development step, the silicon-containing areas serve as an in-situ mask for transferring the patterns through the exposed resist layer creating a positive image.

We have reported such a process for silylation using $193 \mathrm{~nm}$ radiation. The $193 \mathrm{~nm}$ radiation is of sufficient energy to react directly with hydrocarbon bonds causing homolytic, free radical crosslinking of the resist. This is sufficient to generate silylation selectivity under appropriate process conditions. Crosslinking was found to occur in many resist films, including standard novolac/diazoquinone positive photoresist formulations, and novolak resins without any additives.[1] We have found that excellent results can be obtained from appropriate polyvinylphenol films. These materials perform very well in this approach for many of the same reasons that they create problems when incorporated into chemical amplification resists. 
Figure 1. Schematic of $193 \mathrm{~nm}$ positive-tone silylation process.

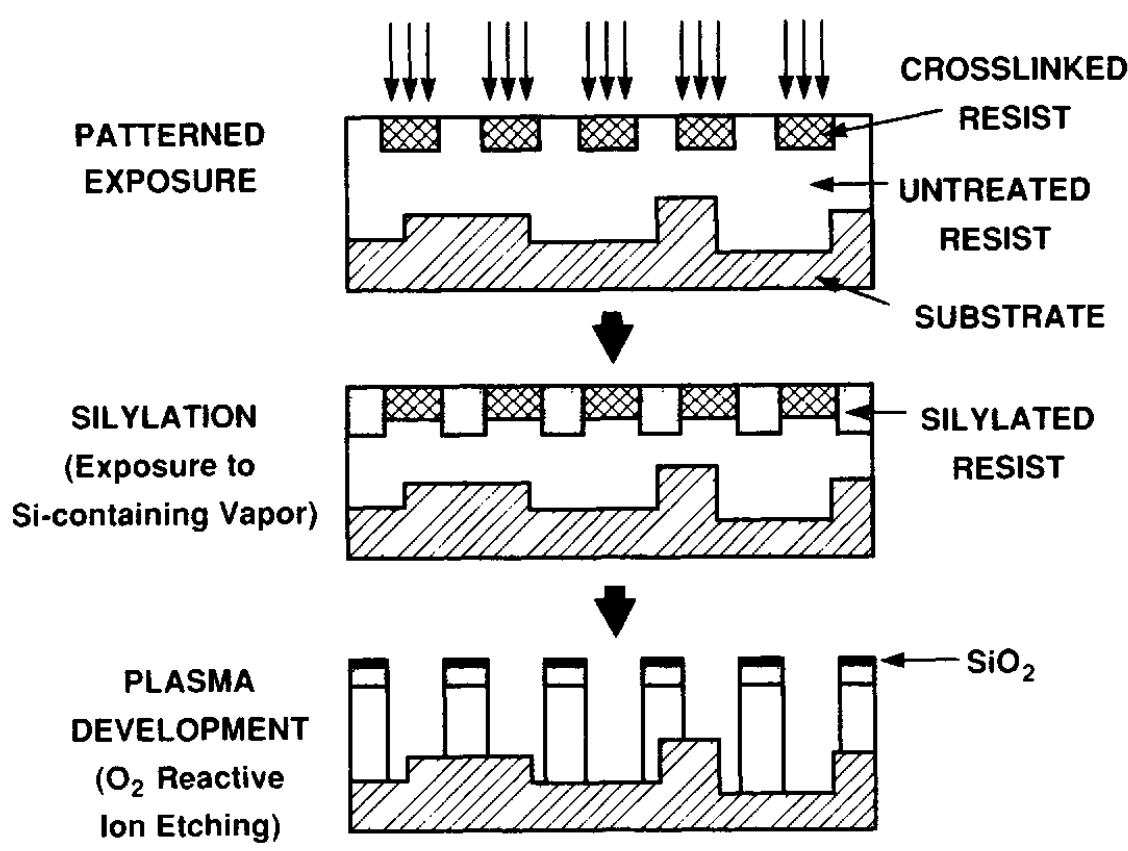

Amines diffuse very rapidly into polyvinylphenol. Silylamine compounds are active silylating agents and have been effectively used at temperatures of 80 to $140^{\circ} \mathrm{C}$. The use of dimethylsilyldimethylamine (DMSDMA) and trimethylsilyldimethylamine (TMSDMA) as silylating agents has been found to proceed rapidly at acceptable temperatures and treatment times (1-4 min). DMSDMA is preferred because of its smaller bulk volume, but TMSDMA is preferred on a cost basis.

\section{EXPERIMENTAL}

Commercial resists were obtained from Microlithography Chemical Company. Both Nano ${ }^{\text {TM }}$ MX-P7 and Nano TM MX-P8 were used for these evaluations. GPC measurements were obtained on a Perkin-Elmer Series 3 Liquid Chromatograph using a Progel-TSK, mixed pore size organic resin column, THF mobile phase, $0.5 \mathrm{ml} / \mathrm{min}$ flow rate, and a $275 \mathrm{~nm}$ UV detector.

Resist films were spun to nominal $1.0 \mu \mathrm{m}$ film thicknesses and were softbaked on a hot plate at $90^{\circ} \mathrm{C}$ for 90 seconds. For resist sensitivity measurements, exposures were carried out using $0.3 \mathrm{~cm}^{2}$ areas patterned with an attenuated beam from a commercially available $193 \mathrm{~nm}$ excimer laser. Fluences were measured with a pyroelectric joulemeter. Patterned exposures were carried out on a laboratory projection system with a $5 \mathrm{X}$ reduction, $0.33 \mathrm{NA}$ catadioptric lens or on a prototype $0.50 \mathrm{NA}$ catadioptric exposure system.

Silylation was carried out in a stainless steel vacuum chamber with an aluminum baseplate, heated with resistive heater cartridges. A vacuum oven, vapor prime unit, or single wafer vapor prime track system capable of $<50 \mathrm{mT}$ Trr can also be used. DMSDMA was used as the silylating agent for most of these studies. HMDS cannot be used as it requires excessive temperatures and does not give the desired silylation selectivity. Resist samples were placed 
on the hot plate in the vacuum chamber and warmed at the silylation temperature for one minute while the chamber was evacuated prior to introduction of the silylating agent. For DMSDMA a $100^{\circ} \mathrm{C}$ silylation temperature was typically used. For TMSDMA silylation, the temperature was raised to $120-140^{\circ} \mathrm{C}$. Silylating agent was introduced to 10 Torr pressure by means of a pressure control valve from a reservoir maintained at room temperature.

Silylamine can also be introduced by means of an appropriate sized injection of liquid or through incorporation of an appropriately sized vapor reservoir. Reaction time was typically one minute, although longer times can be used. For greater silicon incorporation and higher etch selectivity, the treatment time was increased to $1.5 \mathrm{~min}$. At the completion of the silylation reaction the chamber was evacuated ( $<50 \mathrm{mTorr})$ for one minute then flushed with dry nitrogen.

Resist development (etching) was carried out in a commercially available Lucas/Signatone helicon etch system. The reactor was run at 2000 to $2500 \mathrm{~W}$ rf power, and self bias was established by independently powering the wafer chuck. The rf power to the chuck was operated at 90 to $100 \mathrm{~W}$ resulting in a self-bias of about $-90 \mathrm{~V}$. The oxygen flow rate was run at approximately $50 \mathrm{sccm}$ at $2.0 \mathrm{mT}$ orr pressure. The wafer was backside cooled to $-40^{\circ} \mathrm{C}$ at the start of each run and remained on the chill plate during the entire run. With these conditions, etch rates were obtained approaching $1 \mu \mathrm{m}$ per minute with excellent uniformity across the wafer. No residue was noted anywhere on the etched wafer. Preliminary experiments were etched in an Oxford Plasma Technology $\mu$-Etch parallel plate reactive ion etching system equipped with a roots blower pumping package. The flow rate was held constant at $10 \mathrm{sccm}$ which resulted in a processing pressure of approximately $25 \mathrm{~m}$ Torr oxygen. The $\mathrm{rf}$ power was set to $60 \mathrm{~W}$ which resulted in a self-bias voltage of $-230 \mathrm{~V}$. These conditions produced an etch rate for unsilylated resist of $80 \mathrm{~nm} / \mathrm{min}$. Resist films were typically etched for $15 \mathrm{~min}$, resulting in a nominal $25 \%$ overetch.

\section{RESULTS AND DISCUSSION}

3.1 Resist Performance. Phenolic resins are the primary candidates for $193 \mathrm{~nm}$ surface imaging because of their very high absorbance, presence of reactive sites, and susceptibility to radiation induced crosslinking. Figure 2 shows the UV absorbance spectrum polyvinylphenol which is our prime candidate. Polyvinylphenols have been chosen because they show excellent processing characteristics and rapid silylamine diffusion rates. However, they do show significant molecular weight (MW) effects. A year ago, we evaluated a series of

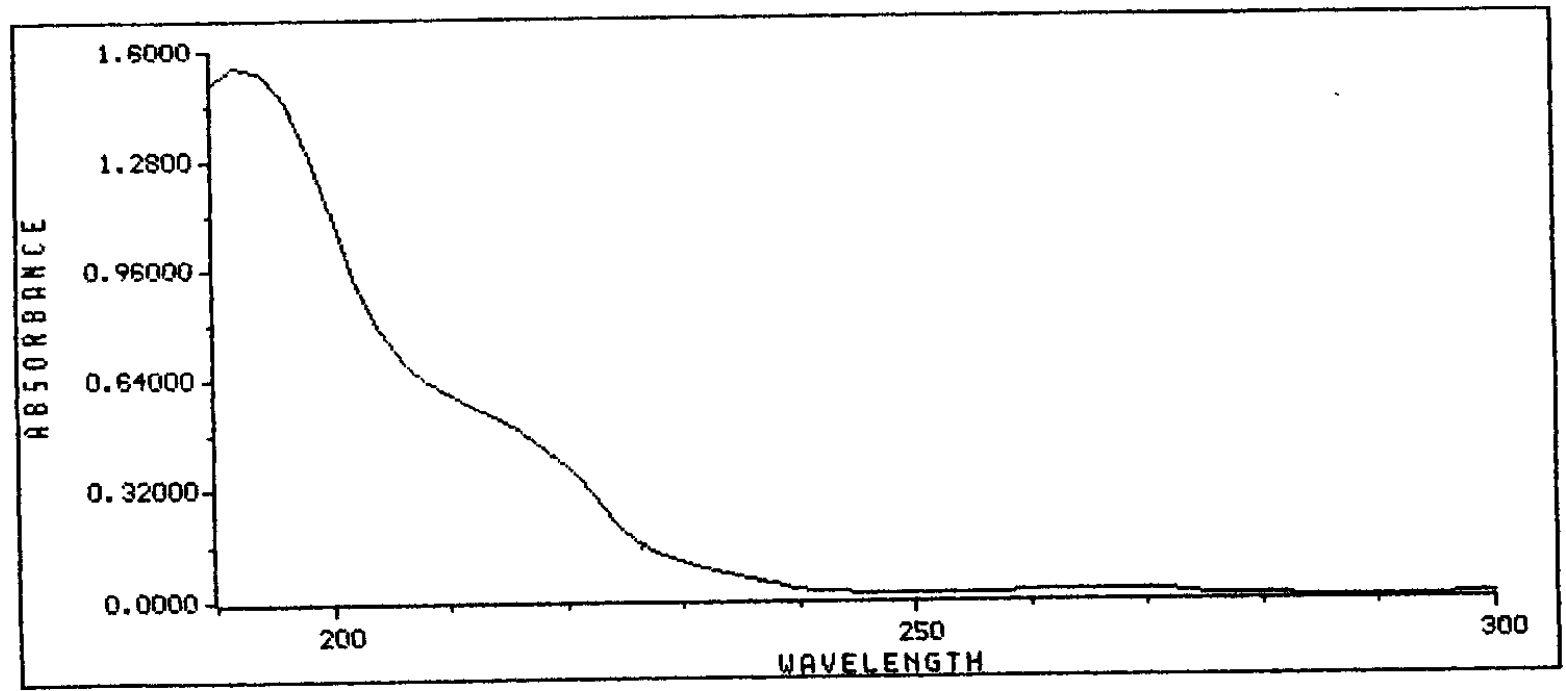

Figure 2. UV Spectrum of poly(4-vinylphenol) 
polyvinylphenol samples with varying MW and MW distribution which were similarly evaluated for sensitivity and ability to silylate. It was found that the higher the MW the higher the sensitivity. We obtained improved sensitivity ranging from $100 \mathrm{~mJ} / \mathrm{cm}^{2}$ to 10 $\mathrm{mJ} / \mathrm{cm}^{2}$ by varying the $M_{W}$ from 6000 to 50,000 as measured by open frame exposures. In all cases, even with the highest MW, lowest dispersivity, and no monomer or dimer content, we could silylate all polyvinylphenol resists under our standard conditions.

However, a puzzling evaluation of $30,000 \mathrm{MW}$ polyvinylphenol from three different commercial sources showed a considerable difference in sensitivity.[5] We obtained sensitivities of 10 to $70 \mathrm{~mJ} / \mathrm{cm}^{2}$ with these three samples. At the time, we felt that the method of preparation could have a significant influence on the performance of these resins. However, our more recent work shows that molecular weight effects appear to be the major contributor to these differences. A re-examination of the molecular weight shows the weight average molecular weight for the three samples actually varied significantly from about 30,000 to about 75,000, Table 1. It can now be seen that open frame sensitivity has a direct relationship to both $\mathbf{M}_{\mathbf{w}}$ or $\mathbf{M}_{\mathbf{n}}$ based on our fixed, standard silylation method.

Table 1. Samples evaluated for $193 \mathrm{~nm}$, surface imaging performance.

$\begin{array}{lrlll}\begin{array}{l}\text { Sample } \\ \text { \# }\end{array} & \mathbf{M}_{\mathbf{n}} & \mathbf{M}_{\mathbf{W}} & \mathbf{M}_{\mathrm{W}} / \mathrm{M}_{\mathbf{n}} & \begin{array}{l}\text { Sens. } \\ \mathrm{mJ} / \mathrm{cm}^{2}\end{array} \\ & 1,930 & 30,900 & 16 & 65 \\ \text { 1(MX-P7) } & 2,430 & 38,000 & 16 & 50 \\ \text { 3(MX-P8) } & 11,200 & 73,900 & 7 & 20\end{array}$

Imaging of MX-P7 after silylation gave excellent results since the silylation conditions were developed with this material. However, when MX-P8 was processed under these same conditions, ragged edges were often noted. Thus, while we had obtained sufficient silicon incorporation for open frame etch selectivity, we had not obtained enough incorporation for good edge definition, particularly in the finer geometries. These results can be explained by our recently published data that shows MX-P7 is silylated 2-2.5 X faster than MX-P8. In the smaller geometries, only marginal amounts of silicon were incorporated and led to an inconsistent etch selectivity along the edges of the image. When we increased silylation conditions so that we incorporate an equivalent amount of silicon into MX-P8, we find equivalent etch results to MX-P7. At these silylation conditions, the photosensitivity of P8 and $\mathrm{P7}$ are now nearly equivalent. More detailed resist evaluations are still needed to determine the relative benefits of P7 and P8. Further refinements in the resist system can be anticipated in future developments. This will be intended to improve overall performance and contrast even further.

3.2 Silylation Results. Silylation of polyvinylphenol resists proceeds rapidly as the relaxation rates of the resin are sufficient to allow rapid diffusion of silylating agents into the film. We have evaluated the diffusion rate of DMSDMA into both unexposed and exposed MX-P7. While it is difficult to get good measurements for the exposed, crosslinked resist because its thickness is only $200-500 \AA$, we were able to get some approximate results. An evaluation of $\log \mathrm{Si}$ vs. 1/T shows the activation energy for diffusion into unexposed resist is about $12 \mathrm{Kcal} / \mathrm{mol}$, while the activation energy for the crosslinked film is $35-40 \mathrm{Kcal} / \mathrm{mol}$. It also appears that the diffusion mechanism changes from a Type II diffusion for unexposed resist to a Type II/craze mechanism for the crosslinked material. In no case, did we observe a total absence of silicon in the crosslinked film. However, under the process conditions used, the amount incorporated into the crosslinked resist is so low that it is completely removed 
Figure 3. Diffusion and swelling of MX-P7 with DMSDMA.

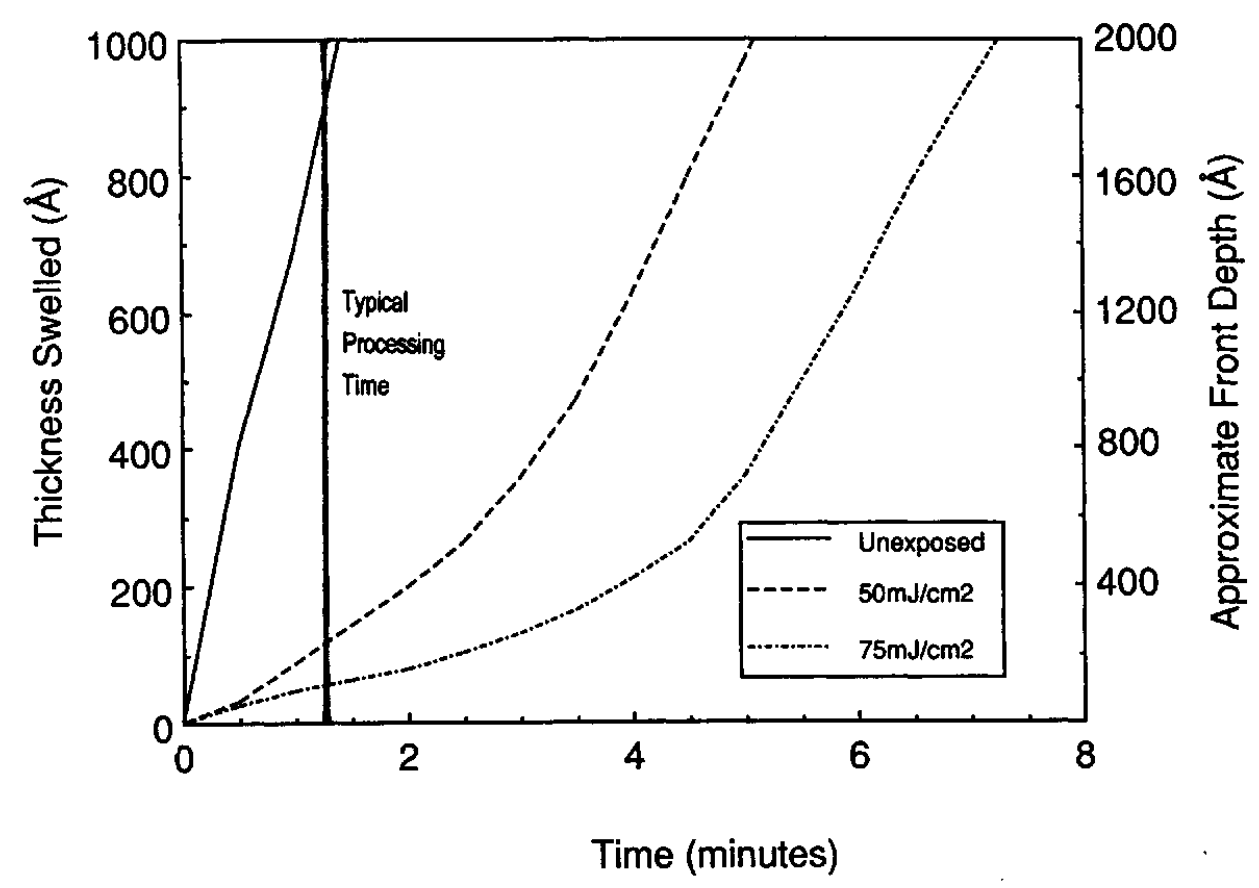

during the etch process. In Figure 3, we show the swelled thickness of MX-P7 as measured by interferometry and the estimated depth of penetration vs. time for open frame silylation. A rapid swelling is noted with unexposed resist, and a much slower growth is seen with exposed resist for short silylation times. At long silylation times (or higher temperatures and pressures) significant silylation of exposed, crosslinked resists does indeed become significant.

It is also known that the depth of silylation varies with the size of the imaged area.

Incorporation of silylating agent leads to an increase in the volume of the silylated region, and this increase is greater in the larger features than in fine features. Ideally we would like to get a very high density of silicon atoms to reduce swelling volume and increase etch selectivity. However, this is limited by the size of the silyl group. For our purposes, dimethylsilyl is the smallest available reactive group and, therefore, the preferred silylating ingredient. However, we find in practice that there is little difference in swelling between dimethylsilyl and

trimethylsilyl substituents. As we reported earlier, there is a significant difference in diffusion rate between DMSDMA, TMSDMA and TMSDEA,[1] also indicating that DMSDMA is the preferred silylating agent. However, we now find that if we increase silylation conditions, so that all three silylamines give the same silicon content in the resist film, as measured by FTIR, we obtain virtually the same image quality for all three agents.

Silylation time, temperature and pressure can be adjusted to give the necessary depth of silylation to provide adequate etch resistance and selectivity in the oxygen plasma development process. With our standard RIE process we have found that approximately 300 $\AA$ silylation depth is sufficient to provide etch selectivity. However, for better etch selectivity greater silicon incorporation is required. In practice, a minimum of $500-1000 \AA$ in the finest geometries are used to provide robustness to the process and to allow for overetch requirements. By making appropriate adjustments in silylation conditions, we can easily evaluate a range of products in this process.

Flow of silylated resist is not seen in either MX-P7 or MX-P8. This is contrary to recent reports for silylated chemically amplified systems, $[10,11]$ as well as for the Plasmask resists. 
The chemically amplified systems contain a mixture of phenolic resin and a low MW crosslinking agent. The uncrosslinked resist has a rather low $\mathrm{Tg}$ which is made even lower when silylated. Quite possibly the $\mathrm{Tg}$ of these silylated, chemically amplified resists can be below room temperature. Because of this, swelled material in the silylated region tends to flow out over the edge of the crosslinked, unsilylated surface. In very fine geometries, two silylated areas can flow into one another over the crosslinked intervening region leading to poor resolution and unopened images. In larger geometries, flow can lead to significant changes in image dimensions and edge profiles.

Both MX-P7 and MX-P8 are high MW polymers with high glass transition temperatures. For MX-P7, the starting resin has a Tg of $160^{\circ} \mathrm{C}$ and after silylation, this is reduced to around $130^{\circ} \mathrm{C}$. For MX-P8, the silylated resin has a Tg of $160^{\circ} \mathrm{C}$. Residual solvent in the film after coat and bake could lower the $\mathrm{Tg}$ another $50^{\circ} \mathrm{C}$ or so. The estimated $\mathrm{Tg}$ of the silylated cast film is $75-100^{\circ} \mathrm{C}$ for MX-P7, and above $100^{\circ} \mathrm{C}$ for MX-P8. Even with the reduction of Tg after silylation, we are still processing below the region of flow for our process times. Figure 4 shows typical examples of swelled images in MX-P7 with no flow. No flow is seen even when the resist is swelled many times larger than would typically be used for standard processing.

Figure 4. Swelled silylated $0.25 \mu \mathrm{m}(2 \mathrm{~min})$ and $0.8 \mu \mathrm{m}(2 \& 4 \mathrm{~min})$ images in MX-P7 resist showing no flow.
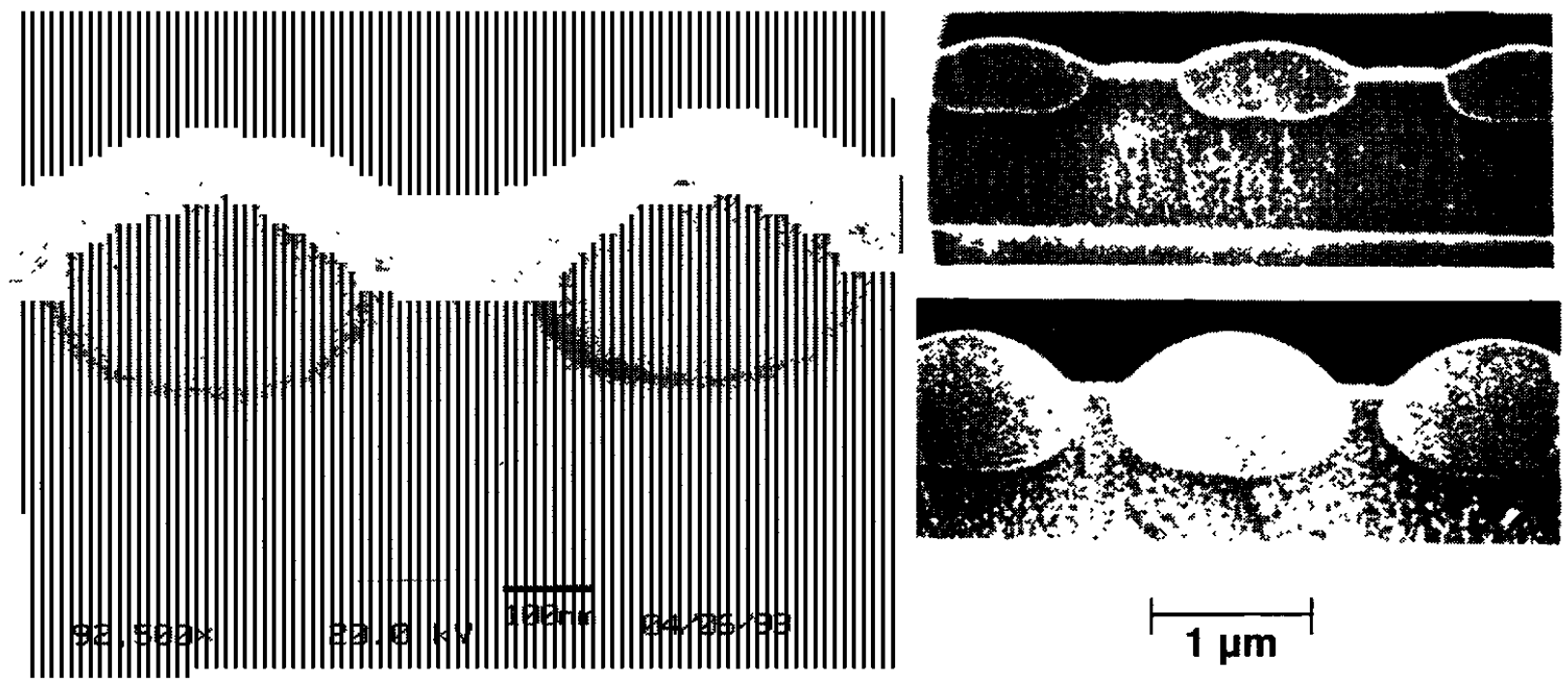

3.3 Delay Effects. The effects of processing delays on the performance of chemical amplification resists has become a major issue because of the large change in image profiles with amine absorbance. We have begun a study to look at several points of interest with $193 \mathrm{~nm}$ polyvinylphenol resists. The first concern was the change in diffusion rate of silylamines as a function of delay time and resist solvent. A set of wafers were coated with polyvinylphenol cast from ethyl lactate, 2-methoxypropyl acetate, and tetrahydrofuran and baked at $90^{\circ} \mathrm{C}$ for 90 seconds. Coated wafers were then allowed to stand for up to one month and evaluated periodically using our standard silylating conditions. The results are shown in Figure 5. We see that all three coatings show the same silicon incorporation (within experimental error), even though one would expect the residual solvent content of the three to be different. Upon standing, the silicon content incorporated becomes less, as the diffusion is being inhibited. All three coatings showed essentially the same decrease. We measured a 1$2 \%$ reduction per day, which does not impact the process for at least 10 days after coating.

At the same time, we found no noticeable change in resist sensitivity, although small changes would not have been detected in these early experiments. We have frequently held wafers for 
Figure 5. Silicon incorporation by FTIR $\left(926 \mathrm{~cm}^{-1}\right)$ in MX-P8 vs. lag time between coat/bake and exposure. Coating solvent: 1. Ethyl lactate, 2. PGMEA, and 3. THF.

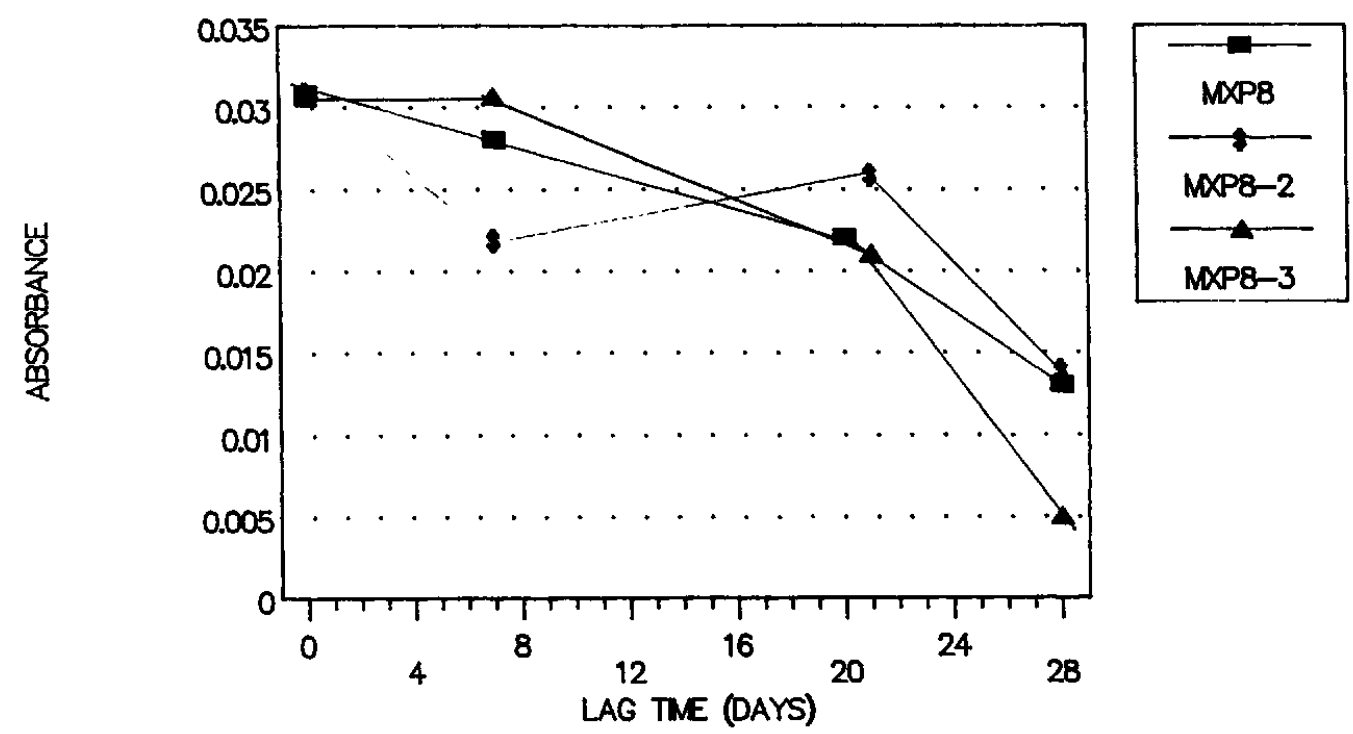

several weeks after exposure, and again have found no significant effects. We do find a slight drop in silicon content upon standing after silylation, but again have found no significant etch effects after standing for one week. Image profiles of rapidly processed substrates cannot be distinguished from those where frequent delays in processing were incorporated.

3.4 RIE Development. Control and cleanliness of the oxygen RIE etch process is really the controlling factor in determining the overall process performance of these surface imaging resists. Research to date has shown excellent results, particularly with the newer helicon and ECR systems.[12] Excellent results have also been shown with a TPC system using other resists.[11] Etch (process) contrast is extremely high, and is very much higher than the silylation contrast. Thus it is apparent that a threshold silicon content is required to provide an etch barrier. The silicon content required will depend on the overall etch process used, with a milder etch process requiring less silicon content. Once sufficient levels of silylation have been reached we see no further change with increased silicon content. Further, we find that edge erosion during the etch is also independent of excess silicon and, therefore, is independent of image dimension down to at least $0.2 \mu$. Etch selectivities of up to 50:1 have been seen with MX-P7 and MX-P8.

3.5 Lithographic Performance. Initial evaluation of process, focus, and exposure latitude were conducted on a 0.22 NA experimental exposure unit. The results were extremely encouraging and have been previously published. New experiments are now being conducted on $0.5 \mathrm{NA}, 193 \mathrm{~nm}$ prototypes of the Micrascan 92 and preliminary data indicates resolution better than $0.18 \mu \mathrm{m}$ and linearity to $0.20 \mu \mathrm{m}$. More detail on a full lithographic evaluation will be published in the near future.

Exposure doses in the 50 to $150 \mathrm{~mJ} / \mathrm{cm}^{2}$ range have provided excellent performance using both MX-P7 and MX-P8 resists. We have obtained $0.2 \mu \mathrm{m}$ images in both without the use of phase shift masks. The SEM of $0.25 \mu \mathrm{m}$ images obtained in MX-P7 using a binary chrome mask and unoptimized helicon etch is shown in Figure 6. With phase shifting we have obtained $0.1 \mu \mathrm{m}$ images, as shown in Figure 7. Ultimate resolution of this process is expected to be better, once the exposure systems reach design specifications and process conditions are optimized. 
Figure 6. $250 \mathrm{~nm}$ Images from 0.50 NA exposure System. Figure 7. $100 \mathrm{~nm}$ Images in MX-P7 using Phase Shift.

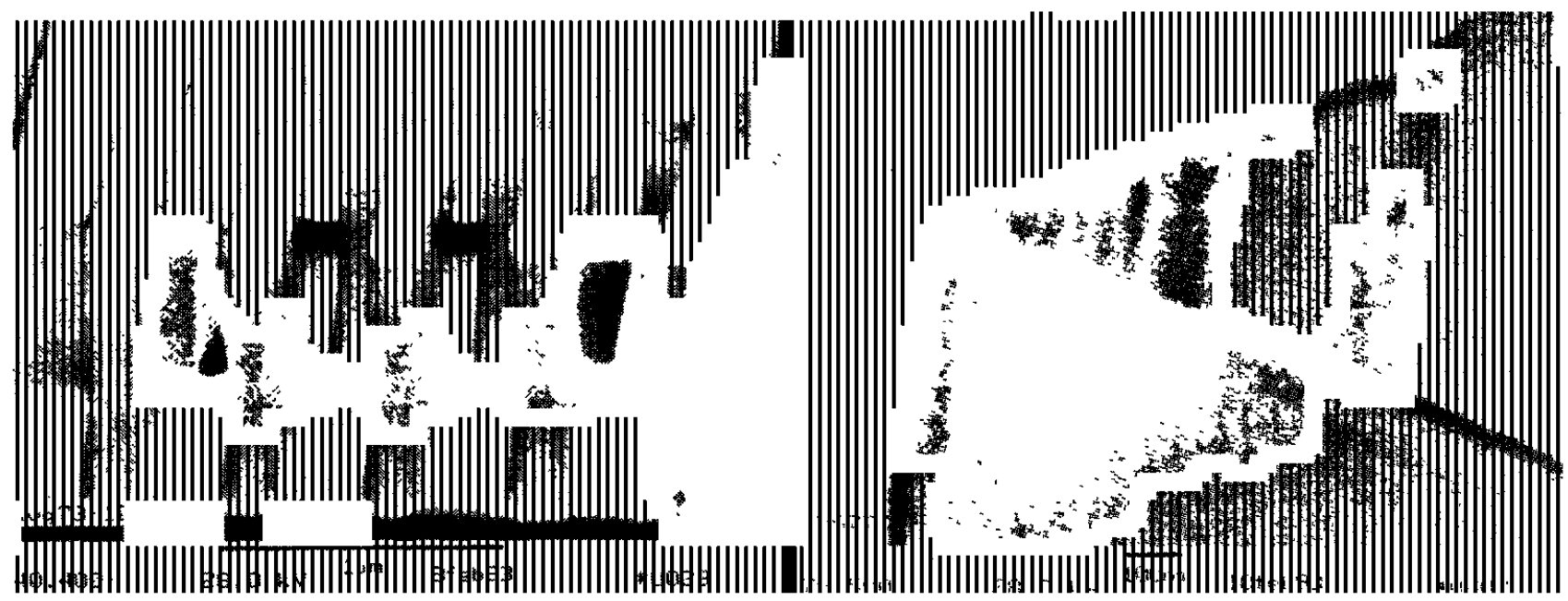

\section{CONCLUSIONS}

Our efforts provide sufficient experimental results to indicate that polyvinylphenol based resists will be the leading candidates for surface imaging, silylation processing with $193 \mathrm{~nm}$ lithography. We have demonstrated that a resist process using MX-P7 and MX-P8 is already available for evaluation of $0.20 \mu \mathrm{m}$ device processes as well as $256 \mathrm{MB}$ DRAM circuits.

We need to further determine the process conditions which give optimized processing parameters. We need to define the impact of softbake temperature, silylation temperature and pressure, and etch conditions on the ultimate performance of these resists. Ultimately, we expect to have a production viable process using $193 \mathrm{~nm}$ lithography and a surface imaging polyvinylphenol-based photoresist available for commercialization in the near future.

\section{ACKNOWLEDGMENTS}

The authors would like to thank Ms. L.M. Eriksen of MIT Lincoln Labs for her assistance in resist processing and Mr. F. Zernike of SVG Lithography for use of the 193 exposure equipment. Also we would like to thank Mr. D. Elliott of Excimer Laser Systems for helpful discussions. The Lincoln Laboratory portion of this work was sponsored by the Advanced Research Projects Agency.

\section{REFERENCES}

1. M.A. Hartney, D.W. Johnson, A.C. Spencer, Proc. SPIE, 1466, 238 (1991).

2. M.A. Hartney, R.R. Kunz, D.J. Ehrlich, D.C. Shaver, Proc. SPIE, 1086, 119 (1990).

3. M.A. Hartney, M. Rothschild, R.R. Kunz, D.J. Ehrlich, D.C. Shaver, J. Vac. Sci. Technol. B, 8, 1476(1990).

4. M.A. Hartney, M.W. Horn, R.R. Kunz, M. Rothschild, D.C. Shaver, Microlithography World, 1, 16(1992)

5. D.W. Johnson, M. Hartney, Jap. J. of Appl. Physics, 31, 4321(1992) and reference therein.

6. D.W. Johnson, D.J. Elliott, Proc SPIE, 1925 to be publ. (1993).

7. R.A. Kunz, R.D. Allen, W.D. Hinsberg, G.M. Wallraff, Proc SPIE 1925, to publ. (1993).

8. Y. Kaimoto, K. Nozaki, S. Takechi, N. Abe, Proc. SPIE, 1672, 66 (1992).

9. M. Endo, K. Hashimoto, K. Yamashita, A. Katsuyama, T. Matsuo, Y. Tani, M. Sasago,

N. Nomura, (presented at the 1992 IEDM Conference, San Francicsco, $14-18$ Dec. 1992).

10. E.K. Pavelchek, G.C. Calabrese, B.W. Dudley, S.K. Jones, P.W. Freeman, J.F. Bohland, R. Sinta, Proc SPIE, 1925, to be publ. (1993).

11. W.S. Han, J.H. Lee, J.C. Park, Y.B. Koh, Proc SPIE, 1925, to be publ. (1993).

12. M.W. Horn, M.A. Hartney, R.R. Kunz, Proc. SPIE, 1672, 448 (1992). 